\title{
Llamados a amar, reflexiones antropológicas
}

Called to love, anthropological thoughts

\author{
Juan José Pérez-Soba Diez del Corral ${ }^{1}$ \\ Pontificio Instituto Teológico Juan Pablo II
}

Recibido: 03.12.2020

Aceptado: 17.12.2020

\section{Resumen}

Solo el atrevimiento característico de la sabiduría nos impulsa a tomar el camino más complejo de pensar en el amor, pues nos hace conscientes del error de querer construir lo principal de la existencia en un sentimiento blando como la arena, incapaz de resistir cualquier contradicción de importancia. Encontrar el auténtico fundamento de esa pregunta, que en la actualidad no se puede dar por descontado, es la única manera de edificar la casa del hombre sobre roca, y apartarnos de la necedad de levantar un edificio sin cimientos. Es una elección trascendental que, como el Papa Benedicto XVI ha señalado con fuerza, tiene una repercusión social de máximo relieve.

Palabras clave: Teología, Antropología, Sagrada Escritura, Existencialismo, Ética

\section{Abstract}

Only the characteristic daring of wisdom prompts us to take the more complex path of thinking about love, since it makes us aware of the error of wanting to build the main thing in existence

${ }^{1}$ perezsoba@istitutogp2.it 
in a feeling soft like sand, unable to resist any contradiction of importance. . Finding the true foundation of that question, which at present cannot be taken for granted, is the only way to build the house of man on rock, and get away from the folly of erecting a building without a foundation. It is a momentous choice that, as Pope Benedict XVI has strongly pointed out, has a social impact of the utmost importance.

Keywords: Theology, Anthropology, Sacred Scripture, Existentialism, Ethics

“«¿Me amas?» Posiblemente esta sea la pregunta más importante que cualquier persona dirige en la vida. Una pregunta arriesgada, pero llena de promesas y de vida. De esta forma el amor, en la existencia de cada persona, especialmente en su juventud, toma la forma de una pregunta. Por ser una pregunta tan íntima, le damos muchas vueltas antes de pronunciarla, nos da mucho que pensar, hace surgir otra multitud de cuestiones que la hacen posible o que la contienen y que tienen que ver con temas esenciales de la vida y la sociedad"2.

Frente a una amalgama de voces que nos invitan a todo tipo de consumo de experiencias o de productos, existe una voz más humilde que no quiere pronunciarse en público, sino que busca un momento especial, porque, consciente de la riqueza del contenido que oculta, quiere ser significativa pues sabe que transmite un mensaje del todo especial incomparable.

Hallarnos ante un acto de tal categoría es un descubrimiento en el que nos jugamos mucho. Ante el hastío del bombardeo de llamadas comerciales, meramente consumistas, ante el cansancio de mandatos imperiosos de aquellos que detentan el poder, ya sea político, económico o de comunicación, por el que nos sentimos simplemente utilizados por intereses en el fondo ajenos a nuestros deseos más profundos; existe todavía un espacio en donde resuena esta voz diferente que defiende su originalidad profunda frente a las demás voces que le rodean.

\footnotetext{
${ }^{2}$ L. Melina, "Introducción", en PonTIFICIO Instituto JuAn PABlo II, Aprender a amar. 30 preguntas para no equivocarse en la aventura más importante de la vida. Jornada Mundial de la Juventud 2011, BAC, Madrid 2012, IX.
} 
Es la llamada al amor. Una experiencia fundamental que aparece en la vida humana y que requiere una reflexión para acertar en ella. Por consiguiente, hemos de atrevernos a pensar en el amor. Podría parecer que es una obviedad, pero que, por el contrario, es una actividad poco frecuente, "en determinados ámbitos sociales se evita casi por principio hablar de los afectos, en especial del amor. Nadie lo hace para explicar un programa político, y mucho menos para mostrar las estrategias económicas. No hace falta casi explicar el porqué de ello: estamos tratando un tema serio; tanto, que no se puede dejar a algo tan subjetivo y voluble como el amor"3. Reducida así la pregunta al ámbito privado, el romanticismo la ha convertido en meramente irracional y censura de raíz cualquier intento de consideración de la misma por parte de la razón ${ }^{4}$. El resultado es una grave debilidad que padece el hombre en el momento de hacerse las preguntas fundamentales sobre el sentido de la vida, en consecuencia, una gran desorientación en lo que corresponde a los pilares firmes donde fundar la propia existencia.

Solo el atrevimiento característico de la sabiduría nos impulsa a tomar este camino más complejo de pensar en el amor, pues nos hace conscientes del error de querer construir lo principal de la existencia en un sentimiento blando como la arena, incapaz de resistir cualquier contradicción de importancia. Encontrar el auténtico fundamento de esa pregunta, que en la actualidad no se puede dar por descontado, es la única manera de edificar la casa del hombre sobre roca, y apartarnos de la necedad de levantar un edificio sin cimientos. Es una elección trascendental que, como el Papa Benedicto XVI ha señalado con fuerza, tiene una repercusión social de máximo relieve, no podemos equivocarnos en la aventura principal de la vida, a pesar de una confusión reinante: “evitar la confusión con los otros tipos de unión basados en un amor débil se presenta hoy con una especial urgencia. Sólo la roca del amor total e irrevocable entre un hombre y una mujer es capaz de fundar la construcción de una sociedad que llegue a ser una casa para todos los hombres"

\footnotetext{
3 J. J. PÉREZ-SOBA, "La renovación moral de la vida económica", en XXIII Encuentro en la cultura -XXI Congreso internacional diálogo fe-cultura, Universidad La Laguna -Instituto Superior de Teología de las Islas Canarias, Las distintas realidades de la crisis, La Laguna (Tenerife) 23-27 de abril de 2012.

${ }^{4}$ Una reflexión sobre este hecho en: J. J. PÉREZ-SOBA, "Status quaestionis: l'amore ci fa pensare”, en J. J. PÉREZSOBA -L. GranAdos (eds.), Il logos dell'agape. Amore e ragione come principi dell'agire, Cantagalli, "Amore umano, 4", Siena 2008, 19-59.

${ }^{5}$ BENEDICTO XVI, Discurso con ocasión del XXV aniversario de la fundación del Pontificio Instituto Juan Pablo II para los Estudios sobre el Matrimonio y la Familia (11-V-2006). Para la relevancia social del amor: cfr. J. J.
} 


\section{Pregunta y llamada}

No podemos confundirnos, aunque la exclamación “¿Me quieres?” tiene forma de pregunta, es el modo delicado de asegurar a la otra persona una verdad previa sin la cual el interrogante pierde todo su significado. Es decir, preguntar a otra persona si nos quiere, es un modo muy directo de decirle "te quiero". Por eso, la pregunta no es sino una cobertura de la llamada al amor. Existe un amor que nos llama y en la respuesta a esta llamada está oculta nuestra razón de vivir.

El Beato Juan Pablo II nos enseñó a hacerla la guía de nuestro camino, tras indicarnos desde el principio de su Pontificado que el hombre tiene una vocación al amor: "El hombre no puede vivir sin amor. Él permanece para sí mismo un ser incomprensible, su vida está privada de sentido si no se le revela el amor, si no se encuentra con el amor, si no lo experimenta y lo hace propio, si no participa en él vivamente"6. Una verdad que Benedicto XVI ha confirmado, precisamente en lo que corresponde a su valencia social: "Todos los hombres perciben el impulso interior de amar de manera auténtica; amor y verdad nunca los abandonan completamente, porque son la vocación que Dios ha puesto en el corazón y en la mente de cada ser humano"7.

Ya puestos en marcha, el primer paso en este camino es muy especial, consiste, precisamente en pararse, en reflexionar sobre lo que se vive para percibir toda su verdad. "La existencia del hombre es verdaderamente humana solo porque llega a elevarse por encima del ritmo del universo y grita: «ipárate!» Lo que distingue al hombre del resto de la creación visible es su propensión a retraerse de la danza cósmica y preguntar por el sentido de todo: «¿Qué me dices?»"

PÉREZ-SobA -M. MAGdič (eds.), L'amore principio di vita sociale. "Caritas aedificat” (1Cor 8,1), Cantagalli, Siena 2011.

${ }^{6}$ JUAN PABLO II, C.Enc. Redemptor hominis, n. 10. Interpreta esta cita como teológicamente central en la encíclica: G. MARENGO, "Amo perché amo, amo per amare". L'evidenza e il compito, Cantagalli, Siena 2007, 22-23.

${ }^{7}$ Benedicto XVI, C.Enc. Caritas in veritate, n. 1. Se comprende su valor antropológico: cfr. J. L. LoRDA, "Claves teológicas para una lectura de Caritas in veritate", en Scripta Theologica 42 (2010) 101-120.

${ }^{8}$ C. Anderson -J. Granados, Called to love. Approaching John Paul II's Theology of the Body, Doubleday, New York 2009, 2. 
Pararnos significa aquí "volver sobre nosotros mismos" (cfr. $L c$ 15,17), hacernos conscientes de un sentido para vivir, es esa especie de soledad primera necesaria para afirmar después el amor. Como nos ha enseñado Juan Pablo II, solo cuando Adán se percibe diferente al resto del mundo es cuando emprende una búsqueda de un sentido que no se le ofrece ni en las delicias del jardín del Edén, ni en el dominio sobre los animales ${ }^{9}$. Es cierto, ni la satisfacción, ni el poder responden a esa búsqueda interior que solo acaba con el despertar propio del amor.

La experiencia radical del amor es una respuesta a una llamada, pero se vive como un despertar $(\text { cfr. Gen } 2,23)^{10}$. No podía ser de otra manera, porque es así como contiene una revelación, un sentido nuevo de la existencia que no procede de un cálculo ni de una deducción, sino de la aparición del amado en toda su presencia fascinante.

Este hecho no parece presentar dudas, la originalidad de la experiencia del amor, su irreductibilidad respecto de cualquier otra que no la puede sustituir, son realidades vividas tan íntimamente que pueden superar cualquier modo cínico de acercarse a ella. "Se puede afirmar con certeza que no existen no creyentes en lo que respecta al amor. Toda persona que ama, y todos aman algo, aunque amen mal, como nos recuerda San Agustín ${ }^{11}$, cree en tal amor, aunque no sea en su totalidad. La dificultad estriba en saber en qué tipo de amor se cree, y en este sentido el cristiano, naturalmente, tiene una ventaja enorme porque sabe realmente en qué amor cree, porque le ha sido revelado con un contenido y una profundidad excepcionales dentro de una relación personal estable. La fe tiene aquí el significado de vincularse al misterio interno del amor como el medio adecuado para una plenitud de vida. En el amor la fe y la vida están radicalmente unidas" $" 12$.

\footnotetext{
${ }^{9}$ Lo que denomina "soledad originaria": cfr. JUAN PABLO II, Hombre y mujer lo creó, Cristiandad, Madrid 2000, 78-86.

${ }^{10}$ Cfr. Ibidem, cat. 15.

${ }^{11}$ Ante todo, porque se define por el objeto querido: cfr. SAN Agustín, De diversis quaestionibus, q. XXXV, 1 (CCL 44 A,50): "Nihil enim aliud est amare quam propter se ipsam rem aliquam appetere".

12 J. J. PÉREZ-SOBA, "Una nuova apologetica: la testimonianza dell'amore. L'enciclica «Deus Caritas est» di Benedetto XVI", en Anthropotes 22 (2006) 160.
} 
El amor nos abre a un misterio ${ }^{13}$ en el que la verdad de cada persona se halla implicada, la importancia de este hecho es tal que ningún rechazo cínico es capaz de romper el profundo vínculo que se establece entre amor y verdad ${ }^{14}$, de forma que nos encontramos con la base firme donde poder edificar la propia vida.

\section{Su contenido: una comunión de personas}

Si el primer paso en nuestro camino era pararnos, el segundo es percibir de qué modo resuena en nuestro interior el amor como una pregunta. No es sencillo decirle a una persona "te quiero”. “¿Qué dice una persona cuando se vuelve a otra y le declara «te quiero»? No solo le está revelando una interioridad, sino que se está diciendo una cosa a sí mismo. La posibilidad de expresarse de este modo no es una simple proposición, sino un modo de afirmarse a sí mismo. Esto nos indica dos dimensiones inherentes a la experiencia del amor que representan las direcciones principales del camino a recorrer" ${ }^{\prime 15}$.

La primera consiste en la necesidad de interpretar nuestra intimidad para descifrar lo que pasa en ella. La ambigüedad con la que se vive en la actualidad el amor no se debe al amor mismo, sino al hecho de que a veces no se sabe poner palabras a los afectos. Las personas no saben lo que les pasa en su interior, ni a dónde les dirigen sus sentimientos. Este fenómeno, que Bauman ha denominado "analfabetismo afectivo" 16 , tiene como consecuencia una intimidad fragmentada que no sabe discernir entre la multitud de afectos que nos llegan el verdadero significado de estos. En cambio, el amor nos habla de la presencia en nuestro interior del amando. Es precisamente esta realidad fabulosa la que nos maravilla hasta el punto de convertirse en una llamada insistente a nuestra atención e intención.

\footnotetext{
${ }^{13}$ Cfr. J. J. PÉREZ-SOBA DIEZ DEL CORRAL, El amor: introducción a un misterio, BAC, Madrid 2011.

${ }^{14}$ Cfr. J. J. PÉREZ-SOBA DIEZ DEL CORRAL, "La verdad del amor: una luz para caminar. Experiencia, metafísica y fundamentación de la moral", en ID., La gloria de Dios y el camino del hombre. Jalones para la renovación moral, Edicep, Valencia 2010, 97-160.

${ }^{15}$ J. J. PÉREZ-SoBA, Il mistero della famiglia, Cantagalli, Siena 2010, 199. De este capítulo titulado “L'esperienza d'amore: tra soggettività e norme sociali" (pp. 199-210) tomo las reflexiones posteriores.

${ }^{16}$ En su libro: Z. BAUMAN, Amores líquidos. Acerca de la fragilidad de los vínculos humanos, Fondo de Cultura Económica, Madrid 2005. Para el tema: cfr. L. Melina, Por una cultura de la familia. El lenguaje del amor, Edicep, Valencia 2009.
} 
En segundo lugar, nace la necesidad de comunicar nuestro querer a la otra persona. Con ello, aparece un nuevo sentido de necesidad que no está en contradicción alguna con la libertad. Recibir una llamada, en especial la llamada del amor, hace imposible la indiferencia. No responder a la llamada es ya un modo de respuesta, pues incluye siempre un acto de libertad. Requiere entonces sopesar toda una serie de razones internas que hacen razonable el amor. Decidir preguntarle al otro “¿me amas?” es, por tanto, percibir toda una serie de razones que le pueden ser significativas y que ha de poner en juego para llamar su atención y reclamar con éxito su amor. "Es cierto que esta exigencia, inserta en la primera etapa de la experiencia amorosa, introduce en el camino del amor toda una serie de elementos nuevos que tienen un significado personal decisivo. El amor adquiere así un valor objetivo indudable porque debe contar con un contenido que sea comprensible a la otra persona, para que pueda ser aceptado por ella, y su realización sea una confirmación que se transforme en un camino para los dos"17.

Constatamos con admiración que, con la llamada del amor, han entrado en escena dos invitados de gran renombre: la verdad y la libertad. Pero que, lejos de disputar entre ellos, lo han hecho con la armonía que les concede el amor, la verdad del amor guía internamente la libertad porque somos libres para amar.

La lógica propia de la llamada al amor concede así unas nuevas claves que permiten romper con las interpretaciones ideológicas que tienen como primera víctima el amor personal. Esto es vital para la vida humana, y debe ser la mayor precaución que cualquier hombre tenga en cuenta. Siempre hemos de recordar la advertencia de San Agustín: "He encontrado muchos que querían engañar, pero ninguno que quisiera dejarse engañar" ${ }^{18}$. Lo cual nos lleva a decir: "es obvio para todos que no podríamos encontrar a nadie que en su propia vida apueste por un amor falso, pues nadie quiere ser engañado en el amor ya que toca tan profundamente la intimidad humana. Esta duplicidad de preferencias se fundamenta, sin duda, en la existencia de una verdad interior a la acción del hombre que tiene como base el amor. No es sencillo expresar de una

${ }^{17}$ J. J. PÉREZ-SOBA, Il mistero della famiglia, cit., 200.

${ }^{18}$ San Agustín, Confesiones, X, 23, 33 (CCL 27,173); citado en Juan Pablo II, C.Enc. Fides et ratio, n. 25. 
forma convincente que el amor tiene su verdad, pero es imposible negar que el hombre no sabe vivir sino en su búsqueda"19.

Lo primero que falsifica ese amor y, en el fondo, la razón más profunda de la pregunta “¿me amas?", es que se busca una reciprocidad, la respuesta positiva del otro, porque es parte intrínseca de su verdad ${ }^{20}$. No se trata sino de la corroboración de la realidad inicial del amor, que consiste en una presencia y que, por ello, solo en cuanto llega a ser mutua, alcanza toda su plenitud.

Se trata de un elemento tan esencial al amor que el mismo beato Juan Pablo II llegó a hablar de una "ley de la reciprocidad" para dejar claro que es en ella donde se nos revela el misterio más profundo del amor. "El Dios de la Alianza ha confiado la vida de cada hombre a otro hombre hermano suyo, según la ley de la reciprocidad del dar y recibir, del don de sí mismo y de la acogida del otro" ${ }^{21}$. Comprender su significado real, conduce a ver la falsedad de la premisa por la cual mi libertad acaba donde empieza la del otro, y que define al otro como un límite de mi libertad. La auténtica dirección de la libertad a la comunión lleva a entender la reciprocidad como una "alianza de libertades" en la que el otro es una llamada a mi libertad.

Pero hemos de tener en cuenta que esta ley de la reciprocidad no se esclarece en su último valor sino en la revelación del amor de Cristo: "En la plenitud de los tiempos, el Hijo de Dios, encarnándose y dando su vida por el hombre, ha demostrado a qué altura y profundidad puede llegar esta ley de la reciprocidad. Cristo, con el don de su Espíritu, da contenidos y significados nuevos a la ley de la reciprocidad, a la entrega del hombre al hombre"22.

\footnotetext{
${ }^{19}$ J. J. PÉreZ-SOBA, "La verdad de la familia cristiana”, en E. MolinA -T. Trigo (eds.), Matrimonio, familia, vida. Homenaje al Prof. Dr. Augusto Sarmiento, "Biblioteca de Teología, 34”, EUNSA, Pamplona $2011,256$.

${ }^{20}$ Cfr. M. NÉDONCELLE, La réciprocité des consciences. Essai sur la nature de la personne, Aubier, Paris 1942, 9: "Par la fenêtre intermittente qu'offre la réciprocité, nous accédons à l'étude de la personnalité même".

${ }^{21}$ JUAN PABLO II, C.Enc. Evangelium vitae, n. $76 \S 2$.

${ }^{22}$ Ibidem. Para su significado: J. J. PÉREZ-SOBA, "La «ley de la reciprocidad», un principio de teología moral. Estudio de una categoría teológica en Evangelium vitae, n. 76”, en Studia Cordubensia 2 (2009) 5-30.
} 
Se puede buscar la reciprocidad del otro, porque se trata de coincidir con él en un contenido común. La reciprocidad apunta a una realidad muy diversa de un simple pacto de intereses, pues se asienta en la comunicación de un bien objetivo que crea vínculos y los sostiene en su propia estabilidad $^{23}$. Se establece un camino creciente lleno de atractivos en el que consiste la verdad del amor, tal como la describe Nédoncelle:

"En el grado más bajo, el otro responde a mi voluntad de promoción por el simple hecho de que existe y se desarrolla (...) su misma existencia es un retorno.

'Después, la reciprocidad es ya psicológica si el otro percibe mi proyecto (...) Mi intencionalidad amante queda en su presencia (...)

'Un tercer nivel de la reciprocidad es cuando el tú ratifica mi proyecto sobre él. (...)

'En fin, la reciprocidad se completa cuando el amado quiere a su vez mi promoción y se vuelve sobre mí con la misma intención que yo había vuelto hacia él"24.

La reciprocidad es, por consiguiente, un bien tan grande que implica a toda la persona en su búsqueda y configura una dinámica interna al amor que actúa a modo de luz. "Pues el amor no descansa en una recepción o gozo extrínseco o superficial del amado, sino que busca poseer al amado perfectamente, llegando a lo más íntimo de él”25. Esto solo se puede realizar por medio de una acción común en la comunicación de determinados bienes: "En el amor de amistad, el amante está en el amado, en cuanto considera los bienes y los males del amigo como suyos, y la voluntad del amigo como suya, de modo que le parezca que él mismo padece y es afectado por los bienes y los males en su amigo" 26 .

\footnotetext{
${ }^{23}$ Cfr. J. J. PÉREZ-SOBA, “El amor y su relevancia social”, en Teología y Catequesis no 114 (2010) 59-89.

${ }^{24}$ M. NÉDONCELLE, Vers une philosophie de l'amour et de la personne, Aubier, Paris 1957, $30 \mathrm{~s}$.

${ }^{25}$ SANTO TOMÁs DE AQUINO, Summa Theologiae, I-II, q. 28, a. 2: “Amor namque concupiscentiae non requiescit in quacumque extrinseca aut superficiale adeptione vel fruitione amati: sed quaerit amatum perfecte habere, quasi ad intima illius perveniens".

${ }^{26}$ Ibidem: "In amore vero amicitiae, amans est in amato, inquantum reputat bona vel mala amici sicut sua, et voluntatem amici sicut suam, ut quasi ipse in suo amico videatur bona vel mala pati, et affici". Es lo que explica la concordia: cfr. D. ORSUTO, "La concordia del amor «idem velle atque idem nolle»", en L. MELINA -C. ANDERSON (eds.), La vía del amor. Reflexiones sobre la encíclica Deus caritas est de Benedicto XVI, Monte Carmelo -Instituto Juan Pablo II, Burgos 2006, 257-265.
} 
Por consiguiente, la dinámica de la reciprocidad abre a los amantes la grandeza de un bien común que trasciende el bien privado de los individuos. Es lo que se ha de llamar exactamente el "bien de la comunión"27. Hemos de comprender bien la importancia decisiva de este punto, que responde a la dinámica íntima del amor por el que se define como "fuerza unitiva"28, pues el amor no acaba en un sentimiento por muy intenso que sea, sino que solo descansa en la unión real con el amado, respetando siempre la diferencia, pues evita de raíz toda fusión despersonalizante ${ }^{29}$. Aunque anticipada en la verdad del afecto lleno de una presencia del amado que invita a salir de uno mismo, la comunión no existe sino por medio del acto de libertad en el que las personas se dan a sí mismas. La lógica del amor es ahora una "lógica del don" que requiere la gratuidad ${ }^{30}$ y se asienta en la verdad del amor que la sostiene ${ }^{31}$.

La vivencia real de una comunión de personas es algo que se da en un inicio por medio de la familia. Lo cual permite el desarrollo del afecto de pertenencia que es el principio de toda sociabilidad $^{32}$. Se trata de una realidad que se ha revelado imprescindible en la educación, especialmente en su dimensión moral, frente a la visión intelectualista de la autonomía racional, se ha de reivindicar la necesidad de una comunidad de referencia que introduce a las personas al valor trascendente de una cierta tradición ${ }^{33}$.

La "verdad del amor" que se percibía de un modo inicial en la primera experiencia a modo de llamada, queda ahora confirmada por unos elementos objetivos que nos descubren la relación

\footnotetext{
${ }^{27}$ Cfr. L. MELINA, “Actuar por el bien de la comunión”, en L. MELINA-J. NORIEGA-J. J. PÉREZ-SOBA, La plenitud del obrar cristiano, Palabra, Madrid 2001, 379-401.

${ }^{28}$ Es como una definición del amor a partir de Dionisio: cfr. SANTO ToMÁs DE AQUINO, Summa Theologiae, III, q. 28, a. 1, s.c.: “dicit Dionysius, IV cap. de div. nom., quod amor quilibet est virtus unitiva".

${ }^{29}$ Es el sentido que le da Santo Tomás: cfr. ID., In de divinis nominibus, c. 4, lec. 12 (n. 455): "Unitio autem a concretione differt. Est enim amor unitio secundum quod amans et amatum conveniunt in aliquo uno sive illud in substantia utriusque, sicut cum aliquis amat seipsum; sive sit species, sicut animalia quae sunt eiusdem speciei se invicem diligunt; sive sit pratria, sicut compatriotae se diligunt; sive sit quodcumque aliud. Concretio autem ad amorem pertinet, secundum quod ea quae sic uniuntur quantum ad aliquid distincta remanent, scilicet quantum ad divisionem amantis et amati”.

${ }^{30}$ Cfr. BENEDICTO XVI, C.Enc. Caritas in veritate, n. 34.

${ }^{31}$ Cfr. L. MElinA -J. NorIEGA -J.J. PÉREZ-SoBA, Caminar a la luz del amor. Fundamentos de la moral cristiana, Ediciones Palabra, Madrid 2007, 661-667.

${ }^{32}$ Cfr. D. VON HildebRAND, La esencia del amor, Rialp, Madrid 1998, 225-246.

${ }^{33}$ Así: A. MacInTyre, After Virtue. A Study in Moral Theory, Notre Dame University Press, Notre Dame IN 1981 y S. HaUerwas, A Community of Character, Notre Dame University Press, Notre Dame IN 1981.
} 
intrínseca entre el amor humano, la sociedad y las instituciones sociales, las cuales, lejos de ser un obstáculo al amor y sus expresiones, son una ayuda a su reconocimiento social y da cauce a su mejor realización. Si somos llamados a amar ahora esta vocación es fuente de obligación y de deberes que no son ajenos a la realidad del amor, se comprende así de qué forma el amor es fundamento de los mandamientos y el gran defensor de la dignidad del hombre ${ }^{34}$.

Hay que reivindicar con fuerza esta dimensión edificante del amor (cfr. 1Co 8,1) en medio de un mundo que exalta el solo "dejarse llevar" y la simple espontaneidad como si fueran las únicas verdades contenidas en el amor. Pero no se puede nunca olvidar lo nocivo de este procedimiento. Es una experiencia común la constatación de que la aparente neutralidad con la que nuestra sociedad ve las manifestaciones afectivas entre las personas, tal actitud crea una dificultad de establecer un camino común entre las personas. En especial, la reducción de la comprensión del amor a la mera emoción impide comprender el tiempo como una realidad de maduración $^{35}$. El tiempo no es enemigo del amor, no pone ni quita nada en él, simplemente muestra su verdad.

\section{La verdad de un plan de Dios: el amor esponsal}

No todas las comuniones entre personas son iguales, dependen del bien que comunican. Es por ello por lo que la relación hombre y mujer tiene un valor específico como reconoce Benedicto XVI: "en toda esta multiplicidad de significados [del amor] destaca, como arquetipo por excelencia, el amor entre el hombre y la mujer, en el cual intervienen inseparablemente el cuerpo y el alma, y en el que se le abre al ser humano una promesa de felicidad que parece irresistible, en comparación del cual palidecen, a primera vista, todos los demás tipos de amor" ${ }^{\prime 6}$. El hecho de que en la llamada al amor esté incluida la diferencia sexual, abre a un misterio específico en la vida del hombre y que obliga a denominar tal amor como esponsal.

\footnotetext{
${ }^{34}$ Cfr. J. J. PÉREZ-SOBA DIEZ DEl CORRAL, Amor, justicia y caridad, EUNSA, Pamplona 2011.

${ }^{35}$ Cfr. S. Mitchell, Can Love Last? The Fate of Romance over Time, Norton \& Company, New York 2002.

${ }^{36}$ Benedicto XVI, C.Enc. Caritas in veritate, n. 2.
} 
El término esponsal viene del latín spondeo que significa "prometer", es decir, un amor que exige una permanencia y que reclama, por tanto, un ejercicio específico de la libertad. Tal promesa ha tenido siempre en la historia de la humanidad dos características que en nuestra cultura están enturbiadas: ha sido religiosa y pública. Esto obedece a que no se corresponde a un afecto intimista por parte de los amantes, sino a una misión más grande que sus planes que se ha de presentar ante Dios y ante los hombres. La misma diferencia sexual remite a un significado que trasciende el hombre individual, la humanidad como totalidad no es el varón o la mujer, sino que requiere la unidad de ambos. Un significado que incluye la imagen de Dios que reside también en la comunión de personas ${ }^{37}$.

La Iglesia lo ha entendido muy bien al entender la esencia del matrimonio en el consentimiento y expresarlo a modo de promesa, esto es, un com-promiso por parte de los contrayentes. Dicen que sí, no a un afecto particular mutuo, sino a un plan de Dios que es el bien específico que quieren a la otra persona. "El hombre entonces debe realizar una clarificación del amor para poderlo calificar como esponsal. No puede decir simplemente «te quiero» como si fuera equivalente a tener una relación sexual, debe llegar a decir «te quiero como esposo / como esposa» que es un modo de calificar a la persona, un modo que quiere llegar a su identidad"38.

Se trata de verificar la unión específica entre el don de sí y la entrega de la propia libertad. Quien entrega el cuerpo sin comprometer la libertad, miente con su propia carne. La verdad de una entrega requiere un cierto sacrificio, no nace de una absoluta seguridad. Es por ello por lo que quien quiere probarse sexualmente nunca se entrega. Como afirma la Conferencia Episcopal Española, cuando esto sucede, supone: "la separación de sexualidad y amor. La primera pasa a ser un modo de experimentar la satisfacción de un deseo y sus reglas serían las propias de un juego. El amor aparece entonces como algo ajeno que en algunos casos se puede unir a la sexualidad, pero que no la informa desde dentro. Sería necesario «probarse»

\footnotetext{
${ }^{37}$ Cfr. JuAn PaBlo II, Hombre y mujer lo creó, cit., cat. 9.
}

38 J. J. PÉREZ-SOBA, Il mistero della famiglia, cit., 207. 
sexualmente antes de saber si se puede amar de verdad a otra persona. En todo caso, no cabría un amor sin condiciones"39.

En esta entrega emerge la implicación de la totalidad del hombre, que incluye su libertad, y la incondicionalidad de dicho don de sí que contiene el futuro del hombre. Es un modo como el hombre alcanza su plenitud "en el don sincero de sí mismo"40.

Naturalmente, en su contenido se encuentra el significado de la fecundidad que es parte de la verdad de este amor. No se trata de un bien electivo para los cónyuges, sino de una dimensión de su amor para que pueda calificarse como esponsal. El amor nunca se cierra en el círculo de dos, sino que se abre a la recepción de otra persona como un don ${ }^{41}$. Ya lo expresó Platón cuando, en confrontación con el amor homosexual, definía la verdad del eros como: "engendrar y parir en lo bello" 42 .

Es por ello por lo que, en el amor, en cuanto entrega, está contenida la auténtica salvación del hombre, como interpreta adecuadamente Soloviev: "La verdad, como fuerza viva que se apodera de la interioridad del hombre y lo libera efectivamente de la falsa autoafirmación, se llama amor. El amor, como efectiva eliminación del egoísmo es la justificación real y la efectiva salvación de la individualidad. El amor es superior a la conciencia racional, pero sin ella no podría obrar como fuerza interior salvífica capaz de promover la individualidad en vez de suprimirla"43.

"Es una interpretación muy distinta de la simplemente romántica, que piensa que la verdad del «te quiero» reside solo en su intensidad y no requiere ninguna confirmación externa. Según tal propuesta, la afirmación en sí misma bastaría para justificar cualquier acto en la medida en

${ }^{39}$ CONFERENCIA EPISCOPAl ESPAÑOLA, Inst. La familia santuario de la vida y esperanza de la sociedad, n. 31.

${ }^{40}$ CONCILIO VATICANO II, Cons.Pas. Gaudium et spes, n. 24.

${ }^{41}$ Cfr. J.-L. MARION, Le phénomène érotique, Grasset, Paris 2003, 304 : “Le passage à l'enfant ne résulte pas d'une loi biologique ou sociale, mais d'une exigence phénoménologique (...) Les amants passent à l'enfant pour radicaliser l'apparition de leur propre phénomène érotique".

42 Platón, El banquete, $206 \mathrm{E}$.

${ }^{43}$ V. SOLOV’ËV, Il significato dell'amore e altri scritti, a cura di A. DELL'ASTA, La casa di Matriona, Milano $1988,66$. 
que se realizaría «por amor» ${ }^{44}$, olvidando la necesidad de aprender a amar para alcanzar la madurez de un amor que debe expresarse como don de sí.

De aquí la importancia decisiva que tiene la aparición de una especialísima Historia de Amor, la Historia de la Salvación, que se une a un amor originario con un valor universal, así como la presenta el cristianismo. La ambigüedad de toda tradición queda así purificada en un plan de Dios que no ofende la racionalidad humana, sino que la conduce a una plenitud" ${ }^{\prime 4}$.

\section{Su debilidad y su fortaleza}

La vocación al amor, que incluye su propia manifestación, en cuanto llamada a la libertad para vivir su verdad, también revela una de las características más propias de la humanidad: la vulnerabilidad $^{46}$. El amor en un cierto sentido nos hace débiles porque nos llama a algo tan grande que podemos sentirnos incapaces de alcanzarlo con la enorme frustración que esto supone. Además, la reciprocidad que configura la intención amorosa nos deja en manos de otra persona que puede herirnos en lo más íntimo. Es imposible hablar sinceramente del amor sin afrontar el reto formidable del dolor, del sufrimiento y del posible fracaso.

Si hemos dado entrada a las dificultades para realizar en la verdad el amor inicialmente percibido en el afecto, esto nos hace reconocer dentro de nuestra intimidad la presencia del peor de los enemigos del amor y es el miedo a amar. Es este el que nos puede paralizar en el camino y convierte en sospechas interminables lo que antes eran sonidos claros de la llamada al amor.

El miedo nunca es gratuito, tiene que ver con la memoria de fracasos y de sufrimientos que no se quieren repetir. Para muchos aparece la tentación de dejar de amar, al menos de amar en

\footnotetext{
${ }^{44}$ Cfr. C.S. LEWIS, I quattro amori. Affetto, Amicizia, Eros, Carità, Jaca Book, Milano 1990.

45 J. J. PÉREZ-SOBA, Il mistero della famiglia, cit., 209.

${ }^{46}$ Cfr. M. C. NussBaum, The Fragility of Goodness. Luck and Ethics in Greek Tragedy and Philosophy, Cambridge University Press, Cambridge 1986, 2: "It suggests that part of the peculiar beauty of human excellence just is its vulnerability".
} 
verdad, con la implicación personal que requiere. En este sentido, tenía mucha razón Ortega y Gasset cuando en referencia al amor romántico sentenciaba: “desde hace dos siglos se habla mucho de amores y poco del amor" ${ }^{\prime 4}$.

Un modo de gestionar en el miedo es banalizar el amor, quererlo apurar en el simple instante para evitar darle cualquier otro relieve. Es lo que Giddens quiere significar al hablar de "relación pura" 48 que constantemente se puede romper sin que hiera a los interesados. Querer vivir el amor sin que afecte a lo íntimo, reservándose el propio "yo" para que no quede tocado.

Por el contrario, lo que se requiere en este caso es una purificación del amor en su verdad. Como recordaba Benedicto XVI: "Los sentimientos van y vienen. Pueden ser una maravillosa chispa inicial, pero no son la totalidad del amor. Al principio hemos hablado del proceso de purificación y maduración mediante el cual el eros llega a ser totalmente él mismo y se convierte en amor en el pleno sentido de la palabra. Es propio de la madurez del amor que abarque todas las potencialidades del hombre e incluya, por así decir, al hombre en su integridad"49. Se trata de apoyarse en una verdad, para encontrar una dimensión del amor que no pasa. La misma vulnerabilidad del amor se asienta en definitiva en su trascendencia. El amor es una realidad que nunca podemos pretender dominar, pero sí aprendemos a responder a su verdad.

Aquí se manifiesta la mayor fortaleza del amor, pues en cuanto su verdad es analógica, se funda siempre en un amor anterior que es creativo y antecede cualquier respuesta ${ }^{50}$, una llamada original "que procede del silencio" 51 . Esto es la experiencia de un amor originario

\footnotetext{
${ }^{47}$ J. ORTEGA Y GASSET, Escritos sobre el amor, en ID., Sobre el amor, Ed. Plenitud, Madrid 1957, 306.

${ }^{48}$ A. GIDDENS, La transformación de la intimidad: sexualidad, amor y erotismo en las sociedades modernas, Cátedra, Madrid ${ }^{2} 1998$.

${ }^{49}$ Benedicto XVI, C.Enc. Deus caritas est, n. 17. Cfr. J. NoRIEGA, "La chispa del sentimiento y la totalidad del amor", en L. MELINA -C. ANDERSON (eds.), La vía del amor, cit., 267-278.

${ }^{50}$ Cfr. J. J. PÉREZ-SoBA, “La logica, analogica, dell'amore”, en N. REALI (ed.), L'amore tra filosofia e teologia. In dialogo con Jean-Luc Marion, Lateran University Press, Roma 2007, 155-170.

${ }^{51}$ SAn IGNACIO DE ANTIOQUÍA, Ad Magnesios, 8,2.
} 
que nos revela una incondicionalidad absoluta: el hecho de ser hijos que tiene un valor universal y nos abre a un misterio de fraternidad ${ }^{52}$.

De este modo, por encima de las interferencias en la llamada, se apunta a un absoluto, que implica al hombre en la totalidad de su ser. Es precisamente la conciencia la que ilumina la llamada al amor. La conciencia desde su inicio ha sido comparada a una "voz" porque aparece con un valor imperativo, sin necesidad de manifestar del todo sus razones. Ligada al valor de su verdad aparece como el reducto contra todo subjetivismo. Un sentido radicalmente atacado en nuestra sociedad como ya lo denunciaba el beato John Henry Newman, cuando decía: "En nuestro tiempo se ha declarado una guerra encarnizada, diría, casi una conspiración, en contra de los derechos de la conciencia (...) Por derecho de la conciencia entienden el derecho de pensar, de hablar, de escribir y de obrar como se les antoja, sin pensar para nada en Dios (...) Hoy, para una gran parte de nuestro público, precisamente el derecho y la libertad de conciencia dispensan de la conciencia" ${ }^{, 53}$.

La conciencia es esencial para responder a cualquier llamada, pues precisamente por ser una "voz" remite siempre a alguien distinto de la conciencia, tal como insiste nuestro apologeta inglés, hay que comprender la conciencia: "no como capricho u opinión sino como obediencia debida a la Voz Divina que habla en nosotros"54. Que se expresa como: "Para clarificar el carácter trascendente, no puramente subjetivo, de la conciencia, Newman la presenta a menudo como voz divina en nosotros. (...) «Un eco supone una voz; una voz supone un ser que habla. Amo y temo este ser»" 55 . De aquí que se pueda hacer una oportuna aclaración: "Para hablar con precisión se debería decir que la conciencia no es tanto la voz de Dios, cuanto el eco de una voz en nuestra intimidad"56.

\footnotetext{
52 Cfr. J. RAtZinger, La fraternidad cristiana, Taurus, Madrid 1962. Para el hecho radical de ser hijos: J. GRANADOS, La carne si fa amore. Il corpo, cardine della storia della salvezza, Cantagalli, Siena 2010, 101: "Questo significa che si afronta il mistero dell'unione dell'umanità e della divintà in Gesù servendosi di un concetto dinamico di carne attraverso il quale gli uomini sono uniti tra loro nella successione delle generazioni e portati, in ultimo termine, a fare riferminento al Padre di tutti”.

53 J. H. Newman, Carta al Duque de Norfolk, c. 5, Rialp, Madrid 1966, 74.

${ }^{54}$ Ibidem, 79.

${ }^{55}$ G. VelocCI, “Aspetti della coscienza nel pensiero di John Henry Newman”, en Sacra Doctrina 37 (1992) 648.

${ }^{56}$ Ibidem, 685.
} 
Se comprende bien ahora la necesidad de cuidar la resonancia interior de ese eco, para no perder su audición correcta. No se puede hablar de recta conciencia sin hacer referencia a las disposiciones interiores hacia el bien que son las virtudes y que pueden, en este sentido, entenderse como "las estrategias del amor"

La relación con la verdad que salva al amor de su privatización y subjetivización ${ }^{58}$, en la actualidad es el vínculo que impide toda "emotivización” de la conciencia: considerar que algo es bueno simplemente porque me siento bien haciéndolo ${ }^{59}$. Fijarse exclusivamente en el propio sentimiento es un modo de impedir que resuene la voz de Dios, pues se pierde la referencia precisa para reconocer la llamada del amado. En cambio, nuestra cultura y en especial casi todo nuestro sistema educativo, tienden a conformar emotivamente la conciencia personal, desfigurándola y convirtiéndola en presa fácil de la manipulación informativa ${ }^{60}$.

Es aquí donde aparece toda su fuerza y se comprende la radicalidad de la afirmación de San Pablo: "el amor no pasa nunca" (1Co 13,8); que tiene su correlato en San Juan cuando pide: "permanecer en el amor" (cfr. 1Jn 4,16). Esto es debido a la relación que se puede establecer con un amor que siempre nos precede y que, anterior a cualquier condición exterior o cualquier debilidad interior, nos sigue llamando insistentemente.

Es el amor del Padre en la parábola del hijo pródigo ( $L c$ 15,11-32), el amor del buen samaritano que sabe cuidar las heridas $(L c 10,30-37)^{61}$, el amor del buen pastor que carga con la oveja ( $L c$

\footnotetext{
${ }^{57}$ Cfr. P. J. WADELL, The Primacy of Love. An Introduction of Thomas Aquinas, Paulist Press, Mahwah, New Yersey 1992, 90.

${ }^{58}$ Como recuerda: BenEdiCTO XVI, C.Enc. Caritas in veritate, n. 4: "Sin la verdad, la caridad es relegada a un ámbito de relaciones reducido y privado. Queda excluida de los proyectos y procesos para construir un desarrollo humano de alcance universal, en el diálogo entre saberes y operatividad".

${ }^{59}$ Para comprender los pasos de dicha emotivización: cfr. J. J. PÉREZ-SOBA DIEZ DEL CORRAL, "Experiencia y ley: «Experiencia moral y experiencia religiosa»", en ID., La gloria de Dios y el camino del hombre. Jalones para la renovación moral, C. 4, Edicep, Valencia 2010, 163-185.

${ }^{60}$ Cfr. J. J. PÉREZ-SOBA -O. Gotia (eds.), Il cammino della vita: l'educazione, una sfida per la morale, Lateran University Press, Roma 2007.

${ }^{61}$ Cfr. R. TRemblay, "La figura del buon Samaritano, porta d'ingresso nell'enciclica di Benedetto XVI Deus caritas est", en Studia Moralia 44 (2006) 395-411.
} 
$15,5)$ y da la vida por ella ( In 10,11$)$ pues "ha venido para que tengan vida y una vida abundante" (Jn 10,10).

Para superar las interferencias nos es necesaria una buena caja de resonancia donde se pueda distinguir los distintos sonidos. Esto nos conduce a entrar en la intimidad humana en cuanto está habitada por muchas presencias, pero en la que tantas veces es difícil saber discernir su valor. Pero es aquí donde Dios sale en nuestra ayuda, por una presencia muy especial. El mismo Cristo no nos ofrece un amor sin una comunión que lo sostenga, es por eso por lo que nos pide en respuesta no un amor cualquiera sino un amor mutuo que conforma una comunión (Jn 15,12). Se trata de la Iglesia, que así es el reflejo del amor mutuo del Padre y del Hijo: “como el Padre me ha amado, así os he amado Yo, permaneced en mi amor" $(J n 15,9)^{62}$.

De esta comunicación de amor nace la misión de la Iglesia: “como Tú me enviaste al mundo, así Yo los envío al mundo" (Jn 17,19), en la que destaca prominentemente el papel de la familia. Como afirmó Juan Pablo II: "Entre los numerosos caminos, [en los que el hombre es el «camino de la Iglesia»] la familia es el primero y el más importante" ${ }^{\text {63 }}$. Esto conduce a repensar la Iglesia desde la misión recibida de su Esposo, la de ser una Madre que enseñe a amar. Es por ello, por lo que "la Iglesia, animada por el amor divino, vive en un estado de misión permanente" ${ }^{94}$. La misión de enseñar a amar por medio del amor humano que se vive en la familia.

\section{Llamados a aprender y a enseñar a amar}

Sin duda, poder decir que somos "llamados a amar" es una herencia singular de Juan Pablo II que vivió en primera persona. "Esta vocación al amor es, de modo natural, el elemento más

\footnotetext{
${ }^{62}$ Cfr. S. DiAnich, La Chiesa mistero di comunione, Marietti, Torino 1990.

63 JUAN PABLO II, Carta a las familias, n. $2 \$ 1$.

${ }^{64}$ J. J. PÉREZ-SOBA, "Vocazione all'amore e teologia del corpo", en L. MELINA -C. ANDERSON (eds.), Una via sempre attuale: l'intuizione sorgiva del pontificato del Beato Giovanni Paolo II. Atti del Congresso "Verso Cristo”. A 30 anni da Redemptor hominis. Attualità di una via all'uomo, presso il Pontificio Istituto Giovanni Paolo II. Roma, 16-17 ottobre 2009, en Anthropotes 27/1 (2011) 119. Cfr. JUAN PABLo II, C.Enc. Redemptor hominis, n. 20: "La Iglesia in statu missionis, tal como nos ha revelado el Concilio Vaticano II."
} 
íntimamente unido a los jóvenes. Como sacerdote, me di cuenta muy pronto de esto. Sentía una llamada interior en esta dirección. Hay que preparar a los jóvenes para el matrimonio, hay que enseñarles el amor. El amor no es cosa que se aprenda, iy sin embargo no hay nada que sea más necesario enseñar! Siendo aún un joven sacerdote aprendí a amar el amor humano. Este es uno de los temas fundamentales sobre el que centré mi sacerdocio, mi ministerio desde el púlpito, en el confesionario, y también a través de la palabra escrita. Si se ama el amor humano nace también la viva necesidad de dedicar todas las fuerzas a la búsqueda de un «amor hermoso»" $" 65$.

Si somos llamados a amar es porque podemos aprender a amar. Esta verdad debe iluminar las relaciones sociales en las que ahora la familia deja de ser un corpúsculo privado, adquiere el status de paradigma del valor de las relaciones personales, una fuente de una nueva sociedad relacional. Es necesario en todo punto que para que nuestra sociedad sea más humana reconozca los bienes enormes que recibe de las familias bien constituidas, que sepa rentabilizar el enorme "capital social" que representa la familia ${ }^{66}$. Es un hecho que en España la familia es la institución social más valorada con mucha diferencia, pero en cambio vivimos una cultura esquizofrénica que vive de espaldas a este bien común maravilloso ${ }^{67}$.

En definitiva, si estamos llamados a amar, es para renovar el mundo con un amor más grande que él. Para que todo hombre pueda encontrar su vocación al amor, que es el único modo de asegurar el auténtico desarrollo de la sociedad: "En realidad, las instituciones por sí solas no bastan, porque el desarrollo humano integral es ante todo vocación y, por tanto, comporta que se asuman libre y solidariamente responsabilidades por parte de todos. Este desarrollo exige, además, una visión trascendente de la persona, necesita a Dios: sin Él, o se niega el desarrollo,

\footnotetext{
${ }^{65}$ Juan Pablo II, Cruzando el umbral de la esperanza, Plaza \& Janés, Barcelona 1994, 132-133. Para el tema: cfr. L. MELINA -S. GRYGIEL (dir.), Amar el amor humano. El legado de Juan Pablo II sobre el Matrimonio y la Familia, Edicep, Valencia 2008.

${ }^{66}$ Cfr. P. DonATI, Perché "la" famiglia? La risposte della sociologia relazionale, Cantagalli, Siena 2009.

${ }^{67}$ Cfr. C. CAFFARra, Familia e bene comune, Prolusione per l'Inaugurazione dell'Anno Académico 2006-2007 del P.I. Giovanni Paolo II, Città del Vaticano 2006.
} 
o se le deja únicamente en manos del hombre, que cede a la presunción de la auto-salvación y termina por promover un desarrollo deshumanizado" 68 .

“Me amas?” Ya no es solo una pregunta que cada hombre tiene que hacer. Así se dirige también el mismo Jesucristo a cada uno de nosotros. Es con nuestra respuesta como quiere realizar esa alianza definitiva de todo hombre con Dios, construir la auténtica familia humana de los hijos de Dios que puedan vivir gozosamente su fraternidad ${ }^{69}$. Es la respuesta definitiva a la llamada a amar, ante el único Maestro del amor, que nos abre a una misión en la sociedad, la de defender y promover el evangelio del matrimonio y la familia. ¿Podemos dudar en la respuesta? "A quien así nos ha amado, ¿quién no le amará?"”70.

\section{Referencias}

A. GIDDENS, La transformación de la intimidad: sexualidad, amor y erotismo en las sociedades modernas, Cátedra, Madrid 1998.

A. MacInTYRe, After Virtue. A Study in Moral Theory, Notre Dame University Press, Notre Dame IN 1981.

C. Anderson -J. Granados, Called to love. Approaching John Paul II's Theology of the Body, Doubleday, New York 2009.

C.S. LewIS, I quattro amori. Affetto, Amicizia, Eros, Carità, Jaca Book, Milano 1990.

CAFFARRA, Familia e bene comune, Prolusione per 1'Inaugurazione dell'Anno Académico 2006-2007 del P.I. Giovanni Paolo II, Città del Vaticano 2006.

D. VON HILDEBRAND, La esencia del amor, Rialp, Madrid 1998.

G. VELOCCI, “Aspetti della coscienza nel pensiero di John Henry Newman”, en Sacra Doctrina 37 (1992) 648.

J. H. Newman, Carta al Duque de Norfolk, c. 5, Rialp, Madrid 1966, 74.

J. J. PÉREZ-SOBA DIEZ DEL CORRAL, "Experiencia y ley: «Experiencia moral y experiencia religiosa»", en ID., La gloria de Dios y el camino del hombre. Jalones para la renovación moral, C. 4, Edicep, Valencia 2010.

J. J. PÉreZ-SobA DIEZ Del Corral, Amor, justicia y caridad, EUNSA, Pamplona 2011.

J. J. PÉREZ-SOBA DIEZ DEL CORRAL, El amor: introducción a un misterio, BAC, Madrid 2011. J. J. PÉREZ-SOBA -M. MAGDiČ (eds.), L'amore principio di vita sociale. "Caritas aedificat" (1Cor 8,1), Cantagalli, Siena 2011.

\footnotetext{
${ }^{68}$ BENEDICTO XVI, C.Enc. Caritas in veritate, $\mathrm{n} .11$.

${ }^{69}$ Recordamos que los capítulos III y V de Caritas in veritate se titulan respectivamente: "Fraternidad humana, desarrollo económico y sociedad civil" y "Colaboración de la familia humana".

70 "Sic nos amantem, quis non redamaret?": del himno Adeste fideles.
} 
J. J. PÉREZ-SobA -O. Gotia (eds.), Il cammino della vita: l'educazione, una sfida per la morale, Lateran University Press, Roma 2007.

J. J. PÉREZ-SOBA, "El amor y su relevancia social”, en Teología y Catequesis no 114 (2010).

J. J. PÉREZ-SOBA, "La «ley de la reciprocidad», un principio de teología moral. Estudio de una categoría teológica en Evangelium vitae, n. 76”, en Studia Cordubensia 2 (2009).

J. J. PÉREZ-SOBA, "La logica, analogica, dell'amore”, en N. REALI (ed.), L'amore tra filosofia e teologia. In dialogo con Jean-Luc Marion, Lateran University Press, Roma 2007.

J. J. PÉreZ-SobA, "La verdad de la familia cristiana", en E. MolinA -T. Trigo (eds.), Matrimonio, familia, vida. Homenaje al Prof. Dr. Augusto Sarmiento, "Biblioteca de Teología, 34", EUNSA, Pamplona 2011.

J. J. PÉreZ-SobA, "Status quaestionis: l'amore ci fa pensare", en J. J. PÉREZ-SoBA -L. Granados (eds.), Il logos dell'agape. Amore e ragione come principi dell'agire, Cantagalli, "Amore umano, 4", Siena 2008.

J. J. PÉREZ-SOBA, “Una nuova apologetica: la testimonianza dell'amore. L'enciclica «Deus Caritas est» di Benedetto XVI", en Anthropotes 22 (2006).

J. J. PÉREZ-SOBA, "Vocazione all'amore e teologia del corpo", en L. MELINA -C. ANDERSON (eds.), Una via sempre attuale: l'intuizione sorgiva del pontificato del Beato Giovanni Paolo II. Atti del Congresso "Verso Cristo". A 30 anni da Redemptor hominis. Attualità di una via all'uomo, presso il Pontificio Istituto Giovanni Paolo II. Roma, 16-17 ottobre 2009, en Anthropotes 27/1 (2011) 119. Cfr. JUAN PABLO II, C.Enc. Redemptor hominis, n. 20: "La Iglesia in statu missionis, tal como nos ha revelado el Concilio Vaticano II."

J. J. PÉREZ-SobA, Il mistero della famiglia, Cantagalli, Siena 2010.

J. ORTEGA Y GASSET, Escritos sobre el amor, en ID., Sobre el amor, Ed. Plenitud, Madrid 1957.

J. RATZINGER, La fraternidad cristiana, Taurus, Madrid 1962.

J.-L. MARION, Le phénomène érotique, Grasset, Paris 2003.

JUAN PABLO II, Carta a las familias.

JuAN PABlo II, Cruzando el umbral de la esperanza, Plaza \& Janés, Barcelona 1994.

L. Melina -J. NoriegA -J.J. PÉRez-SobA, Caminar a la luz del amor. Fundamentos de la moral cristiana, Ediciones Palabra, Madrid 2007.

L. MelinA, “Actuar por el bien de la comunión”, en L. MElinA-J. NoRIEGA-J. J. PÉREZ-SoBA, La plenitud del obrar cristiano, Palabra, Madrid 2001.

L. Melina, "Introducción”, en PONTIFICIO Instituto JUAN PABLO II, Aprender a amar. 30 preguntas para no equivocarse en la aventura más importante de la vida. Jornada Mundial de la Juventud 2011, BAC, Madrid 2012, IX.

L. Melina, Por una cultura de la familia. El lenguaje del amor, Edicep, Valencia 2009.

Lo que denomina "soledad originaria": cfr. JUAN PABLO II, Hombre y mujer lo creó, Cristiandad, Madrid 2000.

M. C. Nussbaum, The Fragility of Goodness. Luck and Ethics in Greek Tragedy and Philosophy, Cambridge University Press, Cambridge 1986.

M. NÉDONCELLE, La réciprocité des consciences. Essai sur la nature de la personne, Aubier, Paris 1942.

M. NÉDONCELlE, Vers une philosophie de l'amour et de la personne, Aubier, Paris 1957.

P. DONATI, Perché "la" famiglia? La risposte della sociologia relazionale, Cantagalli, Siena 2009. 
P. J. WADELL, The Primacy of Love. An Introduction of Thomas Aquinas, Paulist Press, Mahwah, New Yersey 1992.

PLATÓN, El banquete.

R. TREMBlay, 'La figura del buon Samaritano, porta d'ingresso nell'enciclica di Benedetto XVI Deus caritas est", en Studia Moralia 44 (2006).

S. DiAnICH, La Chiesa mistero di comunione, Marietti, Torino 1990.

S. HAUERWAS, A Community of Character, Notre Dame University Press, Notre Dame IN 1981. S. Mitchell, Can Love Last? The Fate of Romance over Time, Norton \& Company, New York 2002.

SANTO TOMÁS DE AQUINO, Summa Theologiae.

V. SOLOV'ËV, Il significato dell'amore e altri scritti, a cura di A. DELL'ASTA, La casa di Matriona, Milano 1988.

Z. Bauman, Amores líquidos. Acerca de la fragilidad de los vínculos humanos, Fondo de Cultura Económica, Madrid 2005. 